\title{
DEVELOPING INDICATORS FOR CAPTURING THE AIRPORTS DYNAMICS IN REGIONAL AND TOURISM DEVELOPMENT: EVIDENCE FROM GREECE
}

\author{
Dimitrios Tsiotas \\ Agricultural University of Athens, Nea Poli, Amfissa, Greece \\ Spyros Niavis \\ University of Thessaly, Pedion Areos, Volos, Greece \\ Serafeim Polyzos \\ University of Thessaly, Pedion Areos, Volos, Greece \\ Artemis Papageorgiou \\ University of Thessaly, Pedion Areos, Volos, Greece
}

\begin{abstract}
Air transport is an aspect of the transportation and communication sector, it is a capital and technology intensive component of the national economies, and it plays an important role in communication and trade, in tourism development, and generally in the economic and regional development. The major role of air transport in the support of distant communication makes it a valuable tool for the strategic planning and innovative marketing in tourism, especially for tourism policies addressed to international markets. Within this context, this paper studies air transport in Greece and particularly the regional dimension of the Greek air transport, by excluding the metropolitan airports of Athens and Thessaloniki. The paper examines the factors that determine the attractiveness of the Greek regional airports on data referring to air traffic statistics and on available spatial and tourism information. For measuring the regional developmental dynamics of the regional airports in Greece, the paper introduces a composite index, which computes passenger-traffic change, between time periods, by considering an airports' classification. Next, for measuring the airport dynamics in tourism development, an indicator is introduced in terms of the international arrivals and overnights per region. The results of applying the proposed indicators comply with the observations of the common practice and they seem sufficient to be used in other areas of application. The overall approach provides a novel measure for air transport studies and it illustrates the contribution of the small and regional airports to tourism and regional development in Greece.
\end{abstract}

KEYWORDS: peripheral airports, small airports, regional airports, spatial dynamics. 


\section{INTRODUCTION}

The globalisation of the economy is based on the communication and connection amongst various parts in the planet (Polyzos, 2019; Tsiotas and Polyzos, 2018), which is conducted through telecommunications and transportation. Through this way, the distribution of goods, productivity factors, and services and human communication is conducted, promoting trade and economic relations of all kinds. Geographical space is the natural receptor of all such activities that affect their evolution over time due to the cost of overcoming distance and, generally, the spatial constraints (Tsiotas and Polyzos, 2015a).

Different conditions of proximity and accessibility, between regions, induce either positive or negative effects to transportation and the induced economic development and growth, causing consequent regional inequalities. Within this framework, air transport contributes to the smoothing of the regional inequalities' phenomenon. It reduces distances between places, facilitates fast transportation, and contributes to the reduction of transportation costs between distant places (Harrigan, 2010; Tsiotas and Polyzos, 2018).

Airports worldwide vary both structurally and functionally (Harrigan, 2010; Polyzos, 2019; Tsiotas and Polyzos, 2015a,b), a fact which led to the emergence of many of studies dealing with aviation connectivity and airport classification, both in academic (by researchers) and institutional (by entities such as the European Union - EU) level. For instance, in 2005, the EU proposed an airport categorization based on the annual passenger-traffic (European Commission, 2005), which was debated mainly because it didn't include the airports' surrounding information (Heymann, 2005). Other approaches consider criteria related to the airports' operational purpose (e.g. leisure, business trips, etc.) (Graham, 1998; Jarach, 2001). Despite that the relationship between airport functionality and regional development was studied in many papers (Goetz, 1992; Robertson, 1995; Green, 2007; Button et al., 2010), the question "Does economic growth promotes airport development or vice versa?" is still open (Janic, 2017). The existence of an airport induces economic and social benefits (Janic, 2017; Kavoura and Kefallonitis, 2018) to local communities, by providing accessibility to other regions (Brueckneraccessco, 2010; Janic, 2017; Kavoura and Kefallonitis, 2018), which favors the development of economic activities, including those related to tourism (Sellner and Nagl, 2010; Lakshmanan, 2011). The attractiveness of an airport's region is a major development factor, but it may also induce negative economic and environmental externalities due to market failures and to inefficient use of resources (Amoroso and Caruso, 
2010; Allrogen and Malina, 2014; Zak and Getzner, 2014). Moreover, investments in air transport may be unfair transport investments opportunity capital costs and rather low airports' connectivity (Allrogen and Malina, 2014).

Based on the interactions developed between an airport and the region where it is located, it has been shown that various forces determine the airports' functionality in the peripheral regions in comparison with the central areas. On the one hand, the airport operations activate a broad set of economic activities at the region where the airport is located, which promote the economic growth of the region, whereas, on the other hand, in order an airport to operate a significant amount of economic, environmental and policy resources is necessary to be spend (Amoroso and Caruso, 2010; Allroggen and Malina, 2014; Zak and Getzner, 2014). According to the Airports Council International (2004), airports' contribution to the national and regional economy has four aspects:

1. The direct economic effects, which concern the airport activities' benefits (e.g. employment and income increase);

2. The indirect effects, which regard the increase (in the broader regional market) of the airports' supporting activities (e.g. incoming and outgoing transportation, from and to the airport, airport's supply with goods serving operational needs, etc.);

3. The induced effects, which concern the reinforcement of the economy induced by the spend of income generated by the (previously mentioned) direct and indirect effects;

4. The catalytic effects, referring to the economic growth that is generated to the region due to the airport's existence.

Tourism is strongly related to air transport (Bieger and Wittmer, 2006; Khadaroo and Seetanah, 2008). According to Bieger and Wittmer (2006), there is a bidirectional relationship between these two concepts, where attractive regions enhance local air transport while well-interconnected airports promote tourism development. This becomes obvious by examining the effects of the Low-Cost Carriers (LCCS), which result (in many cases) to the emergence of new destinations (Donzelli, 2010). In Greece, regional airports have many peculiarities, comparatively with other European countries, which are related to the rich Greek island geomorphology (it consists of 227 inhabited islands covering 1/5 of the total area), the airports size, seasonality, high interdependence with tourism activity (75\% of international tourist arrivals are conducted by air), and to the fierce competition with other transport modes (Tsiotas and Polyzos, 2015b). It is noteworthy that about $70 \%$ of the 
Greek airports are located in the insular country. This ratio seems to follow the insularmainland tourist accommodation ratio, the odd of which is estimated at about $60-40 \%$ (Polyzos, 2019; Tsiotas and Polyzos, 2015a,b). On the other hand, the lack of efficiency in Greek airports restricts their contribution to regional development (Tsekeris, 2011), due to seasonality (which led to underutilized capacity) and to the lack of advanced management practices (Papatheodorou and Arvanitis, 2009; Psaraki-Kalouptsidi and Kalakou, 2011). Underutilized capacity was hindered by the late emergence of the LCCs in the Greek market (Papatheodorou and Arvanitis, 2009) and by the lack of Public-Private Partnerships (PPPs) (Arvanitis and Papatheodorou, 2015). Recently, a major shift towards private management was the concession agreement for managing 14 regional airports between the Greek government and the Fraport Company (Bellos, 2017).

The major role of air transport in distant communication (Rodrigue, 2013; Tsiotas and Polyzos, 2018; Polyzos, 2019) makes it a valuable tool for the strategic planning and innovative marketing in tourism for tourism policies addressed to international markets. For instance, for a country, a highly developed air transportation network facilitates inbound tourism flows (Tsiotas et al., 2018). Thus, it improves the effectiveness of national strategic tourism planning and tourism policies to attract international tourism. On the other hand, a destination not supported by air transport is restricted in receiving international inbound tourism flows (Rodrigue, 2013; Polyzos, 2019). Thus, the policies aim to develop this destination, in the context of international tourism market, cannot be that effective. Therefore, the profound knowledge of the airport dynamics is an issue of critical importance for strategic planning and innovative marketing in tourism, at the national level.

Within this context, this paper studies the characteristics of 37 Greek regional airports (i.e. excluding the metropolitan of Athens and Thessaloniki), aiming to assess the dynamics of the small and regional airports in Greece and to illustrate their contribution to tourism and regional development. The remainder of the article is organized as follows: Section 2 presents the materials and methods used in the analysis. Section 3 presents the results and their interpretation through the regional and tourism development perspective. Finally, in Section 4, conclusions and some policy proposals are given. 


\section{MATERIALS AND METHODS}

Figure 1 shows the classification of Greek airports, at the national scale. According to this diagram, the Greek airports are first classified into metropolitan and peripheral. This distinction is conducted under a mixed population and geographical criterion because, at the national scale, only the regions of Athens (population: almost 4,000,000) and Thessaloniki (population: over $1,000,000)$ have the critical size to be considered as metropolitan regions and therefore their capital cities to be considered as megacities (Polyzos and Tsiotas, 2012). According to this criterion, the airports of Athens (ATH) and Thessaloniki (SKG) are considered as metropolitan, whereas all the other cases are considered as regional. Due to their outlier performance, in comparison with the size of the regional airports (Tsiotas and Polyzos, 2013), the metropolitan airports of ATH and SKF are excluded from the analysis.

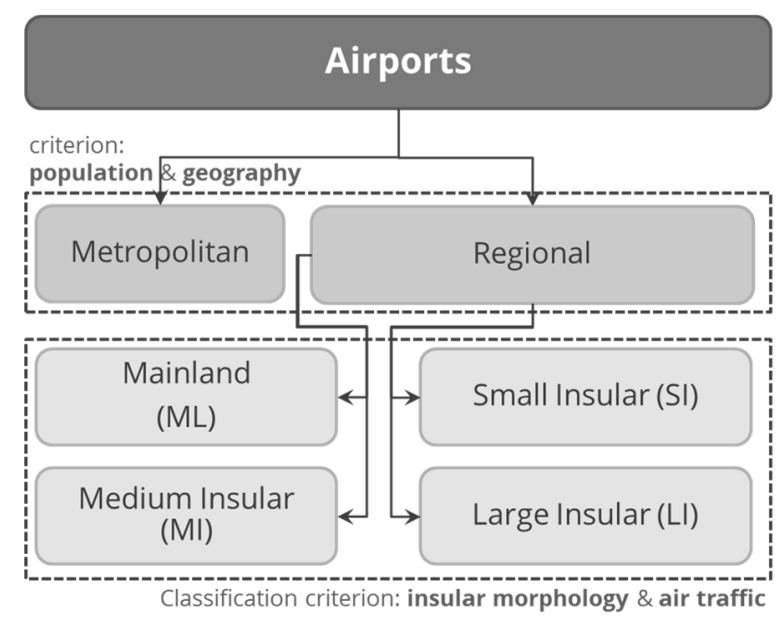

Figure 1. Classification of airports in the national scale of Greece.

For information and data managing purposes, the 37 Greek regional airports are grouped into four categories under a double criterion concerning insularity and annual passengertraffic (data are extracted from the period 1994-2013), according to the information shown in Table 1.

Table 1. Classification of the Greek regional airports

\begin{tabular}{|c|c|c|c|c|c|c|c|}
\hline \multicolumn{2}{|c|}{ Large Insular (LI) } & \multicolumn{2}{c|}{ Medium Insular } & \multicolumn{2}{l|}{ Small Insular (SI) } & \multicolumn{2}{c|}{ Mainland (ML) } \\
\hline \multirow{2}{*}{ Name } & $\begin{array}{l}\text { ICAO } \\
\text { Code }\end{array}$ & Name & $\begin{array}{c}\text { ICAO } \\
\text { Code }\end{array}$ & Name & $\begin{array}{c}\text { ICAO } \\
\text { Code }\end{array}$ & Name & $\begin{array}{c}\text { ICAO } \\
\text { Code }\end{array}$ \\
\hline Zakinthos & ZTH & Karpathos & AOK & Astypalaia & JTY & N.Aghialos & VOL \\
\hline Heraklion & HER & Kefallonia & EFL & Ikaria & JIK & Aktio & PVK \\
\hline Corfu & CFU & Limnos & LXS & Kalymnos & JKL & Alexandroupolis & AXD \\
\hline
\end{tabular}




\begin{tabular}{|c|c|c|c|c|c|c|c|}
\hline \multicolumn{2}{|c|}{ Large Insular (LI) } & \multicolumn{2}{c|}{ Medium Insular } & \multicolumn{2}{c|}{ Small Insular (SI) } & \multicolumn{2}{c|}{ Mainland (ML) } \\
\hline Kos & KGS & Mykons & JMK & Kasos & KSJ & Araxos & GPA \\
\hline Rhodes & RHO & Mytilini & MJT & Kastelorizo & KZS & Ioannina & IOA \\
\hline Santorini & JTR & Samos & SMI & Kithira & KIT & Kavala & KVA \\
\hline Chania & CHQ & Skiathos & JSI & Leros & LRS & Kalamata & KLX \\
\hline & & Chios & JKH & Milos & MLO & Kastoria & KSO \\
\hline & & & & Naxos & JNX & Kozani & KZI \\
\hline & & & & Paros & PAS & & \\
\hline & & & & Stitia & JSH & & \\
\hline & & & & Skiros & SKU & & \\
\hline & & & & Syros & JSY & & \\
\hline
\end{tabular}

The classification of Table 1 is portrayed at the map of Figure 2, which shows the spatial distribution of the regional airports in Greece, according to the category (large insular - LI, medium insular - MI, small insular - SI, and mainland - ML) they belong to.

Figure 2. Spatial distribution of the regional airports in Greece, according to their category.

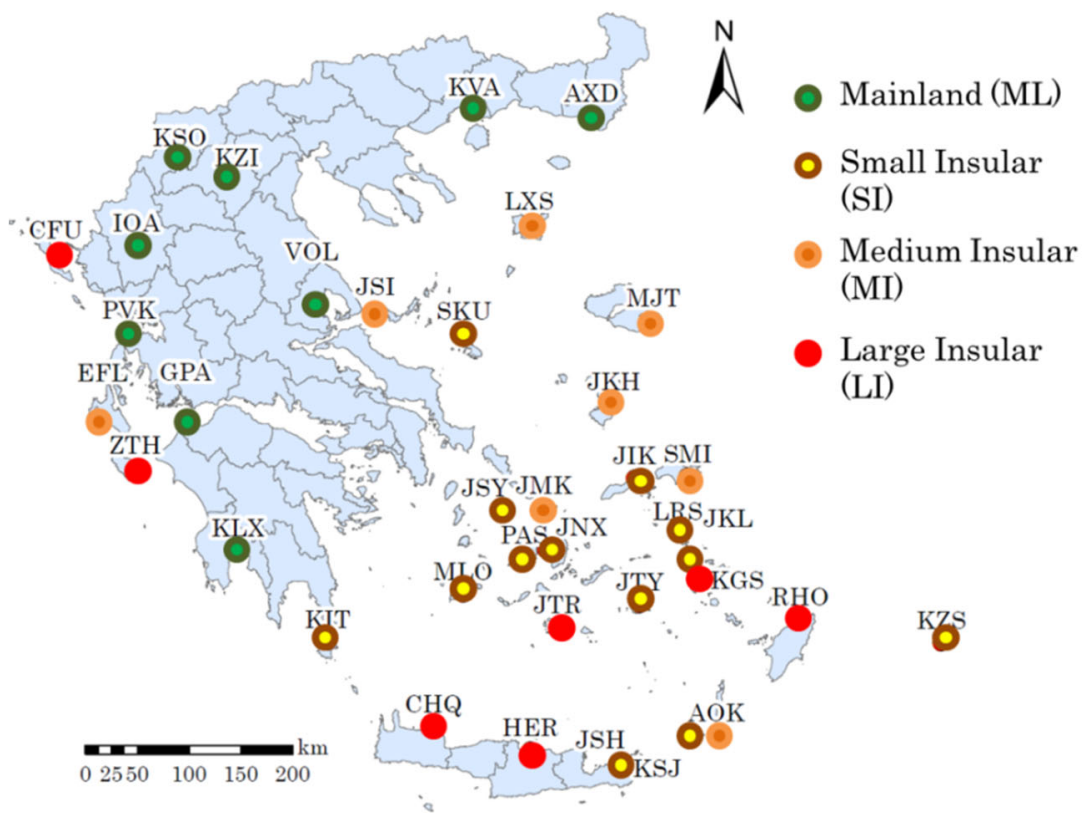

The analysis of this paper is conducted in two stages. At the first stage, the airports' dynamics are modeled according to the passenger-traffic undertaken by each airport. This uni-variable criterion was taken into consideration because passenger-traffic is a major variable determining the size of an airport (Polyzos, 2019; Tsekeris, 2011; Tsiotas and Polyzos 2015b) and also data is most easily available. To measure such dynamics, we introduce a composite multiplier indicator (named Airports Dynamics Composite Index $A D C I$ ), which is defined as follows:

$$
A D C I_{i}=\frac{\Delta x_{i}^{*}}{E\left(\Delta x^{*} \mid x \in G_{i}\right)} \cdot\left(100 \cdot\left(\Delta x_{i} / x_{i, 1994}\right)\right) \cdot \frac{1}{C V(i)}
$$


where

- index $i=1,2, . ., 37$, is the indicator of a regional airport,

- $\Delta x_{i}=x_{i, 2013}-x_{i, 1994}$ is the change in annual passenger-traffic for the years 1994 and 2013, for airport $i$,

- $\Delta x^{*}$ expresses the adjusted changes computed on the transposed differences $\Delta x_{i}^{*}=\Delta x_{i}+\left|\min \left\{\Delta x \mid x \in G_{i}\right\}\right|$ so that all differences to be positive $\left(\Delta x^{*} \geq 0\right)$,

- $G_{i}$ is the category where airport $i$ belongs to (see Table 1 ),

- $|\cdot|$ is the absolute-value operator,

- $E\left(\Delta x^{*} \mid x \in G_{i}\right)$ is the average of $\Delta x^{*}$ (adjusted changes in annual passenger-traffic for the years 1994 and 2013), for all airports included in the same category $G_{\text {ir }}$

- $100 \cdot\left(\Delta x_{i} / x_{i, 1994}\right)=100 \cdot\left(\left(x_{i, 2013}-x_{i, 1994}\right) / x_{i, 1994}\right)$ is the relative passenger-traffic change of airport $i$, and

- $C V(I)$ is the coefficient of variation (see Walpole et al., 2012) computed for all intermediate years included in the period [1994, 2013], for airport $i$, which expresses the homogeneity of air traffic through time in this airport.

The ADCI is developed under a composite rationale, which implements three different measurements. The first is applied within a group of airports, it has a spatial configuration, and is computed by the formula $\frac{\Delta x_{i}^{*}}{E\left(\Delta x^{*} \mid x \in G_{i}\right)}$, which measures the relative size of the traffic-change escalated in accordance with the mean value of the category. For computing this component, differences $\Delta x_{i}$ should be adjusted to the positive set of integers, according to the formula $\Delta x_{i}^{*}=\Delta x_{i}+\left|\min \left\{\Delta x \mid x \in G_{i}\right\}\right|$ (i.e. by adding to all elements the absolute of the minimum value included in the set $\left\{\Delta x \mid x \in G_{i}\right\}$ ). This allows cases above average ( $\Delta x_{i}^{*} \geq E\left(\Delta x^{*} \mid x \in G_{i}\right)$ ) to contribute with a scaling factor greater than one $(\geq 1)$ to the ADCI formula, whereas cases lower than average to cause reduction effects $(<1)$. The second measurement is a relativity component computed by the formula $\left(\left(100 \cdot\left(\Delta x_{i} / x_{i, 1994}\right)\right)\right)$, which computes the relative change of passenger traffic for the starting (1994) and ending (2013) reference years. This component contributes with positive values $(\geq 0)$ when airports increased their traffic comparatively to the starting year and with negative values $(<0)$ otherwise. Zero cases imply a constant performance and they lead to zero scores the overall 
ADCI. Finally, the third measurement has a temporal interpretation and it is computed by using the inverse coefficient of variation $\frac{1}{C V(i)}$, for the total of years included in the period [1994, 2013]. Provided that cases with $C V<0.1$ capture homogeneity (Walpole et al., 2012), the inverse coefficient affects multiplicative the ADCI at a scale more than 10 times. Overall, based on the proposed ADCI, an airport is highly dynamic when it has great positive changes (absolute and relative) of annual traffic and a quite low variability in its performance over time. The ADCI has been composed in a context that high values express high dynamics.

At the second stage, airports are examined in terms of the tourism development existing in their regions. Despite that the effect of an airport (especially for the largest ones) is not limited to its region (Allrogen and Malina, 2014), the use of the administrative division into regions suggests a good proxy for identifying the connectivity strength between airports and local development (Brueckner, 2003). Within this context, the administrative unit of prefecture is chosen as spatial reference in this study for the case of Greece. Two methods are used to capture the relationship between air traffic and tourism development. The first is based on correlation between annual passenger arrivals at airports and tourists' arrivals at the respective prefectures (for the period 2003-2015). Due to limited data availability, the Spearman's correlation coefficient is used (Norusis, 2005). At the second step, the tourism developmental importance of airports is measured by the ratio of the annual foreign tourists' arrivals to the total annual foreign tourists' overnights at the hotels, for a prefecture, as shown in Eq.2.

$\operatorname{THI}_{i}($ Tourism Hub Index $)=\frac{\text { international arrivals at airports of prefecture } i}{\text { international overnights at hotels of prefecture } i}$

The THI captures whether airports are significant in terms of filling the supply of the hotels in their regions. Scores close to one express that an airport acts as a hub for a wider area since the airport arrivals exceed overnights at the hotels. Thus, a part of the foreign tourist flows is being forwarded to adjacent regions (destinations). Data in this part refers to the period 1994-2013 and is extracted (for arrivals) from the Civil Aviation Authority (2018) and (for overnights) from the Hellenic Statistical Authority (2018). Spatial data is extracted from Google Maps (2013). 


\section{RESULTS AND DISCUSSION}

Of the 45 airports constructed in Greece, 39 were active in the reference period (19942013), while the remaining six were out of service. Fig.3 depicts the geographical location of the operational regional airports, and shows their division into geographical quadrants $\left(\mathrm{Q}_{1^{-}}\right.$ $\left.Q_{4}\right)$, where some basic figures, such as density $\left(d_{i}\right)$, share of passenger-traffic $\left(t_{i}\right)$, and some other traffic information is shown. Initially, it is observed that the SI group's spatial distribution extends mainly into the region of the southern Aegean $\left(Q_{4}\right)$, while the MI group extends into the central and northern Aegean region, except for EFL and AOK. Besides, the LI group is located in the southern Aegean and the Ionian seas. Finally, the LI group accommodates half of the total passenger traffic, followed by the MI group airports with $25 \%$.

Figure 3. Spatial distribution and basic traffic figures of the Greek airports

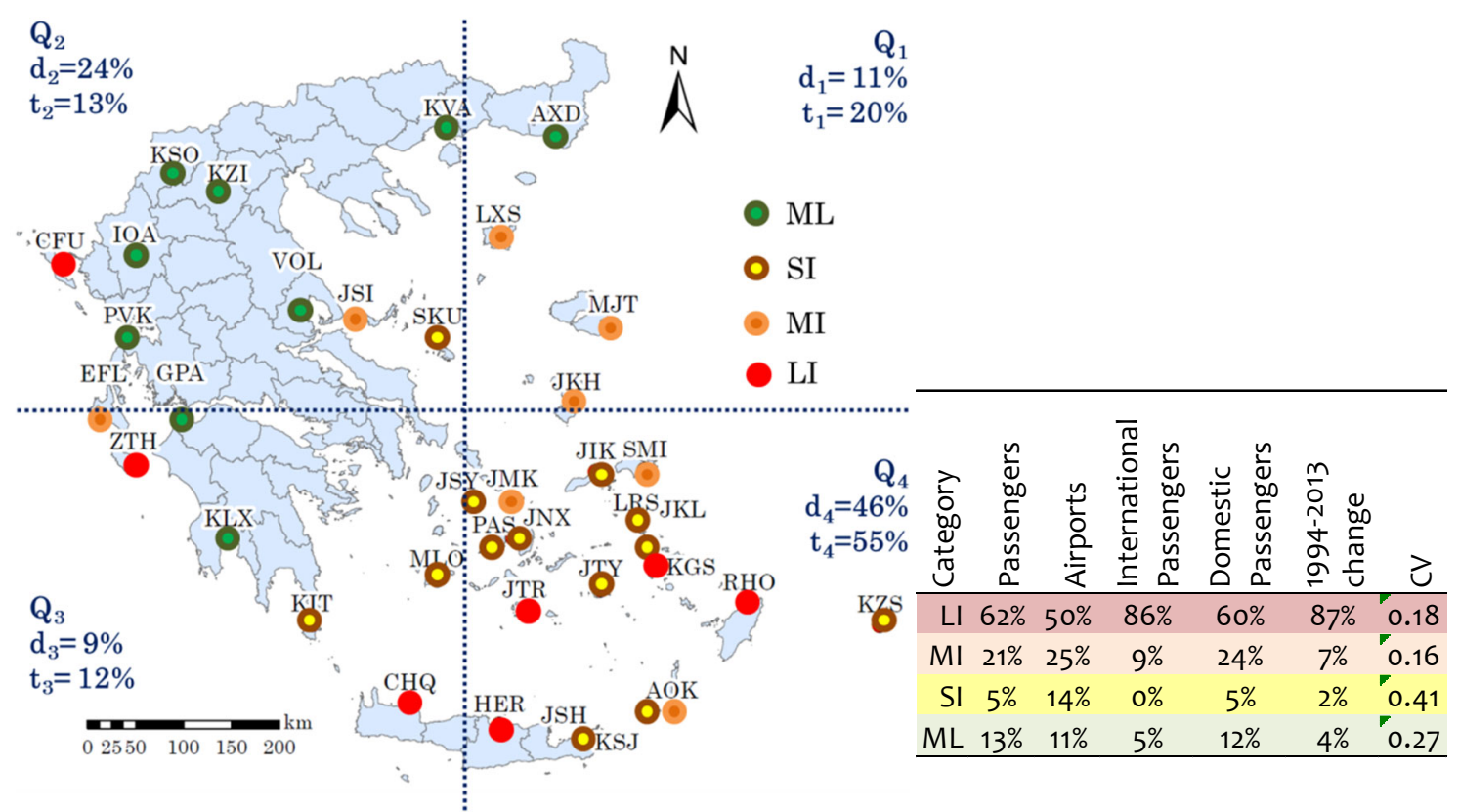

Table 2 shows the results of the ADCI calculations, and Fig. 4 shows a map with the spatial distribution of the ADCI. Initially, the $M L$ cluster included in $\left(Q_{1}, Q_{2}\right)$ shows limited dynamics (negative ADCI values), except the AXD that is positive probably because it serves high domestic traffic and a large number of armed forces operating in the camps. The east and south east Aegean cluster MJT, JKH, JIK, SMI, LRS, JKL, KGS, RHO, and KZS generally shows a positive trend along the route, except SMI (negative ADCI value). Dominant cases here are the RHO and KGS. In addition, the western regional arc of airports CFU, PVK, EFL, GPA, ZTH, KLX, and KIT presents positive prospects, except Corfu (CFU) which shows a lag 
comparatively with the other airports of the LI category. This lag is partially reflected in the CFU's low domestic traffic, which corresponds to $9.66 \%$ of the total and to $67.62 \%$ of the LI's average. In contrast, its international traffic reaches $14.30 \%$ of the total, hovering around the LI's average.

Table 2. Results of the ADCI calculations

\begin{tabular}{|c|c|c|c|c|c|c|c|c|}
\hline & \multicolumn{2}{|c|}{ LI } & \multicolumn{2}{|c|}{ MI } & \multicolumn{2}{|c|}{ SI } & \multicolumn{2}{|c|}{ ML } \\
\hline & Rank & ADCI & Rank & ADCI & Rank & ADCI & Rank & ADCI \\
\hline 1 & $\mathrm{CHQ}$ & 7.377 & JMK & 28.737 & JIK & 86.335 & PVK & 22.630 \\
\hline 2 & $\mathrm{RHO}$ & 7.176 & EFL & 10.113 & $\mathrm{JKH}$ & 38.719 & $\mathrm{VOL}$ & 11.596 \\
\hline 3 & HER & 6.098 & MJT & 0.902 & SKU & 12.111 & KLX & 7.657 \\
\hline 4 & JTR & 2.996 & AOK & 5.024 & $\mathrm{JKL}$ & 10.181 & GPA & 6.792 \\
\hline 5 & KGS & 2.957 & $\mathrm{JKH}$ & 0.007 & JTY & 8.864 & AXD & 0.615 \\
\hline 6 & ZTH & 2.550 & JSI & 0.005 & LRS & 8.740 & KSO & -0.050 \\
\hline 7 & CFU & 0.505 & LXS & -1.009 & KIT & 6.608 & KZI & -0.146 \\
\hline 8 & & & SMI & -2.049 & MLO & 2.456 & KVA & -0.290 \\
\hline 9 & & & & & KZS & 1.675 & IOA & -0.383 \\
\hline 10 & & & & & JNX & 1.449 & & \\
\hline 11 & & & & & KSJ & -0.037 & & \\
\hline 12 & & & & & JSY & -0.292 & & \\
\hline 13 & & & & & PAS & -0.778 & & \\
\hline
\end{tabular}

Figure 4. Spatial distribution of the ADCI index in the map of Greece.

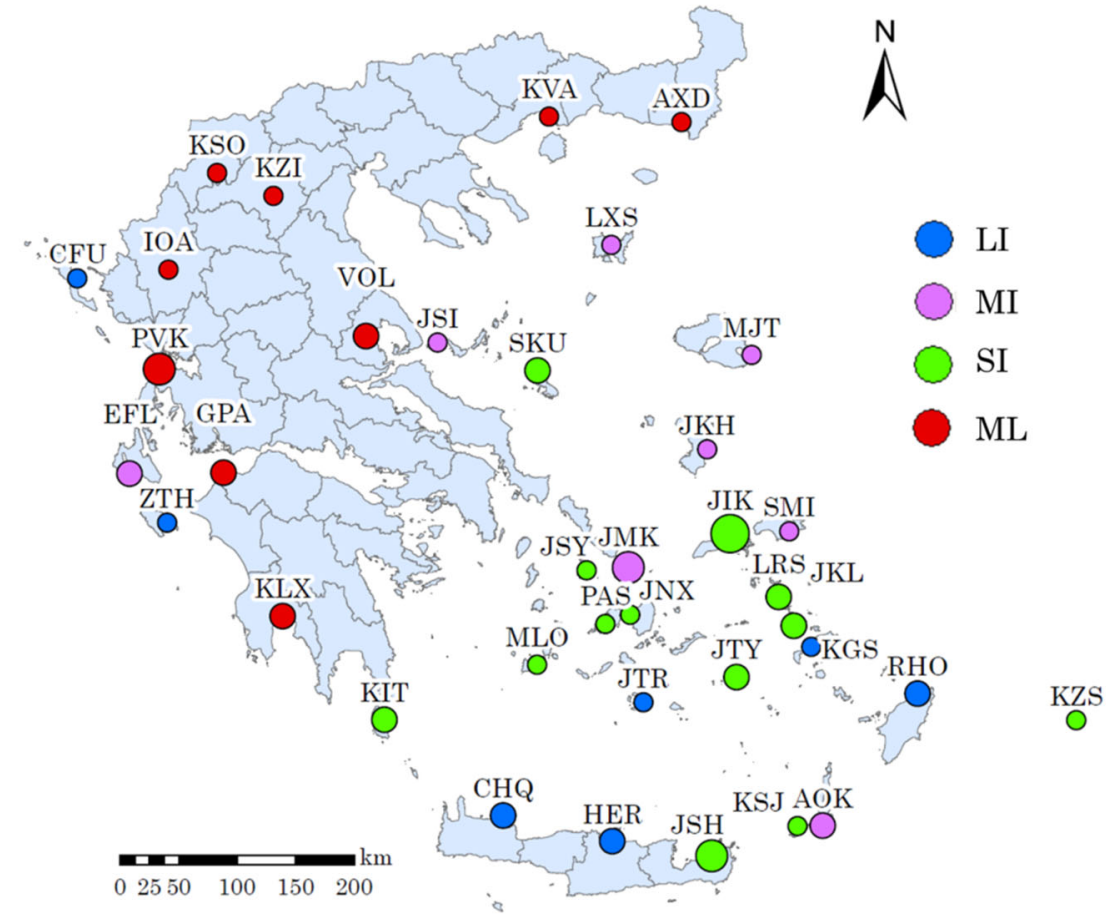

Amongst the other airports, the PVK shows the highest dynamics. The central Aegean airports JMK, JSY, JNX, PAS, MLO, JTR, and JTY show marginally positive trends, since the 
cluster JMK, MLO, JTR, and JTY record a positive performance, the JNX is static, whereas JSY and PAS are negative. Mykonos (JMK) is one with the highest ADCI in the MI category. The group $\mathrm{CHQ}, \mathrm{HER}$, JSH, KSJ, and AOK show positive trends, except KSJ that is marginally static. The major $\mathrm{CHQ}$ and HER airports tap on Crete's high tourism attractiveness, showing high ADCI values within their category. Finally, the airports VOL, JSI, SKU, and LXS show positive dynamics with an explicit geographic configuration. Airports VOL and SKU belong to the highest of their categories, JSI is static, whereas only LXS is negative.

Table 3 shows the Spearman's correlation coefficient calculations, where a significant positive correlation between tourists' arrivals at airports and hotels is captured for 6 out of 21 prefectures. For the other 15 cases, no linear relationship between airport and hotel arrivals is significant. This illustrates that airports have a structural role mainly in serving the islands, especially for the most tourism-developed countries.

Table 3. Spearman's correlation coefficients $(\rho)$ between airport arrivals and hotel overnights, for the Greek prefectures (2003-2015).

\begin{tabular}{|c|c|c|c|}
\hline Prefecture & Airport & $\rho$ & Sig. \\
\hline Kyklades & Kyklades Airports* & 0.925 & 0.000 \\
\hline Dodekanisos & $\begin{array}{l}\text { Dodekanisos } \\
\text { Airports** }\end{array}$ & 0.899 & 0.000 \\
\hline Evros & Alexandroupolis & 0.820 & 0.000 \\
\hline Chania & Chania & 0.820 & 0.000 \\
\hline Heraklion & Heraklion & 0.754 & 0.002 \\
\hline Kefalonia & Kefalonia & 0.503 & 0.067 \\
\hline
\end{tabular}

Moreover, the highest correlations are detected for airports that accommodate rather high passenger-traffic, presenting various alternative flight options to passengers. Therefore, tourism in the regions of Kyklades and Dodekanisos and in the prefectures of Chania and Heraklion appears more sensitive to their airports' performance, comparatively to other continental areas and with several insular destinations (such as Corfu and Zakynthos). This denotes that, in many cases, regional airports are not the major entrance gates for tourists due to competition with other transport modes since many ports operate as gates in insular areas. Finally, the significant result for Evros prefecture is remarkable, implying that hotel arrivals are sensitive to this airport that acts as a gate for tourists' entrance.

Table 4 shows the THI calculation results, and Fig.5 shows a map with the THI's spatial distribution. For 15 cases, the indicator exceeds the critical value of $100 \%$, denoting that 
international arrivals at airports exceed those of hotel overnights at the airports' prefectures. Airports with highest score are in their majority insular (except PVK) and large (in terms of passenger flows). High scores are also observed for the prefectures of LXS, MJT, KVA, VOL, whereas all other cases are far below $10 \%$.

Table 4. Results of the THI calculations

\begin{tabular}{|l|l|l|l|l|l|l|l|}
\hline Airport & $\begin{array}{l}\text { THI } \\
(\mathbf{\%})\end{array}$ & Airport & $\begin{array}{l}\text { THI } \\
(\mathbf{\%})\end{array}$ & Airport & $\begin{array}{l}\text { THI } \\
(\mathbf{\%})\end{array}$ & Airport & $\begin{array}{l}\text { THI } \\
(\%)\end{array}$ \\
\hline PVK & 1071 & KGS & 153 & KVA & 50 & MLO & 0.00 \\
\hline EFL & 232 & GPA & 135 & VOL & 26 & JNX & 0.00 \\
\hline JTR & 229 & CHQ & 134 & JKH & 7.47 & PAS & 0.00 \\
\hline JSI & 227 & RHO & 121 & SKU & 1.58 & JSY & 0.00 \\
\hline HER & 196 & SMI & 109 & AXD & 1.03 & $\begin{array}{l}\text { JKL, JTY, and } \\
\text { LRS }\end{array}$ & 0.00 \\
\hline KLX & 166 & JMK & 105 & KSO & 1.03 & AOK and KSJ & 0.00 \\
\hline CFU & 164 & LXS & 80 & JSH & 0.11 & KZI & 0.00 \\
\hline ZTH & 163 & MJT & 59 & IOA & 0.01 & JIK & 0.00 \\
\hline
\end{tabular}

In general, the tourism-oriented airports are mainly insular and they are acting as gates. Islands with THI $>100 \%$, appear to operate as hubs forwarding traffic to nearby prefectures' destinations. In contrast, regional airports with relatively low THIs are found on destinations where other transport modes mainly direct tourism flows. Thus, they fail to acquire a leading role in their area traffic. For those prefectures, the metropolitan airports ATH and SKG operate as gates for international tourists' arrivals, whereas tourists use other modes to reach their destinations.

Figure 5. Spatial distribution of the THI index in the map of Greece

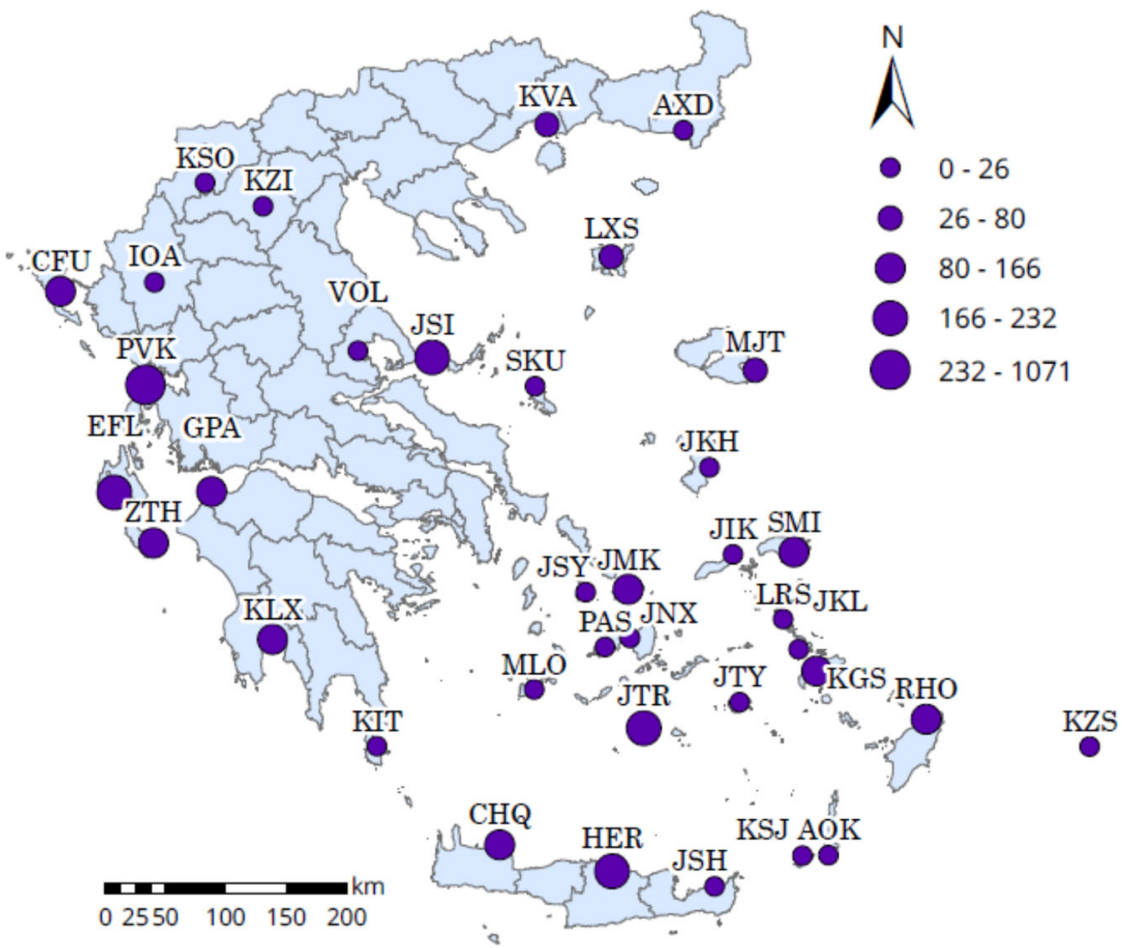




\section{CONCLUSIONS}

This paper examined the dynamics of 37 regional (without ATH and SKG) airports in Greece on traffic and spatial-economic information for the period 1994-2013, aiming to highlight the regional dimension of air transportation and its relationship with tourism. The analysis was based on further grouping into four categories, and it showed a rather concentrated aviation market since $>50 \%$ of the traffic was concentrated in the south-east Aegean region. In contrast, mainland traffic was $<25 \%$. Despite that this empirical research was applied to Greece, a coastal country with significant peripheral island morphology, this paper's methodological framework appears independent to the case study. Thus, it can enjoy further applications either at national, regional, or international levels because the proposed indicators were developed on relative quantities, which are considered scale-free.

In terms of tourism, airports appeared diverse developmental dynamics at different regions. Correlation analysis between airport arrivals and hotel overnights showed that an airport's existence is mostly critical for the most developed tourism regions and lesser critical for other regions, where different transport modes prevail. Moreover, the size of the airports matters, as in most cases, the traffic of the largest airports was more related to the adjacent hotel sector. Additionally, the tourism hub index (THI) calculation showed that larger airports acquired a more strategic role in forwarding international tourism flows. These airports exceeded a critical point of traffic, making them more attractive for passengers due to better connectivity, and thus to operate as hubs for the adjacent prefectures.

Overall, this paper configures a helpful basis for the local authorities to become fully aware of their airports' dynamics and adjust their policies in strengthening their role for the local societies. Moreover, the tourism actors can understand whether the airport plays a dominant role in filling their supply and drive funding and marketing sources for its further enhancement.

\section{REFERENCES}

- Airports Council International - ACI, (2004) The Social and Economic Impact of Airports in Europe, Brussels, York Aviation's Publication.

- Allrogen F, Malina, R, (2014) Do the regional growth effects of air transport differ among airports?. Journal of Air Transport Management, 37, 1-4.

- Amoroso S, Caruso L, (2010) Regional airport: study on economic and social profitability. International Journal of Sustainable Development and Planning 5(2), 175-184. 
- Arvanitis P, Papatheodorou A, (2015) Greek airports in transition: From public ownership to PPP concessions. Journal of Airport Management, 9(3), 284-295.

- Bellos E, (2017) In Fraport since yesterday 14 airports, the price of 1,2 bill, was paid, Daily Newspaper (Kathimerini), available from: http://www.kathimerini.gr/ 904901/ article/ oikonomia/epixeirhseis/sth-fraport-apo-x8es-ta-14-aerodromia-katavlh8hke-totimhma-toy-12-dis.

- Bieger T, Wittmer A, (2006) Air transport and tourism-Perspectives and challenges for destinations, airlines and governments. Journal of air transport management, 12(1), 4046.

- Brueckner J K, (2003) 'Airline traffic and urban economic development', Urban Studies 40(8), 1455-1469.

- Button K, Doh S, Yuan J, (2010) 'The role of small airports in economic development, Journal of Airport Management, 4(2), 125-136.

- Civil Aviation Authority, (2018) Statistical Data (1997-2018), Available from: http://www.ypa.gr/profile/statistics/.

- Donzelli M, (2010) 'The effect of low-cost air transportation on the local economy: Evidence from Southern Italy', Journal of Air Transport Management, 16(3), 121-126.

- European Commission, (2005) Community Guidelines on Financing of Airports and StartUp Aid to Airlines Departing from Regional Airport. Official Journal of the European Union, OJEU-2005/C 312/01.

- Goetz A R, (1992) 'Air passenger transportation and growth in the U.S. urban System, 1950-1987', Growth and Change, 23, 218-242.

- Google Maps, (2013) Google Mapping Services, available from: www.google.gr/maps?hl=el.

- Graham B, (1998) 'Liberalization, regional economic development and the geography of demand for air transport in the European Union', Journal of Transport Geography, 6(2), 87-104.

- Green R K, (2007) 'Airports and economic development', Real Estate Economics, 3(1), 91-112.

- Harrigan J, (2010), 'Airplanes and comparative advantage', Journal of International Economics, 82:181-194.

- Hellenic Statistical Authority, (2018) Hotels, rooms for rent and tourist campsites 19972018, Available from: http://www.statistics.gr/en/statistics/-/publication/STO12/-.

- Heymann E. (2005), Expansion of regional airports: Misallocation of resources, Deutsche Bank Research, November 18. 
- Janic M, (2017) The Sustainability of Air Transportation. A quantitative Analysis and Assessment, London: Routledge.

- Jarach D, (2001) 'The evolution of airport management practices: towards a multi-point, multi-service, marketing-driven firm', Journal of Air Transport Management, 7, 119-125.

- Kavoura A, Kefallonitis E, (2018) The Effect of Social Media Networking in the Travel Industry, In Khosrow-Pour M (Ed.) Encyclopedia of Information Science and Technology, Fourth Ed, IGI Global: 4053-4063.

- Khadaroo J, Seetanah B, (2008) 'The role of transport infrastructure in international tourism development: A gravity model approach,' Tourism management, 29(5), 831-840.

- Lakshmanan T R, (2011) 'The broader economic consequences of transport infrastructure investments', Journal of Transport Geography, 9(1), 1-12.

- Norusis J M, (2005) SPSS 13.0 Statistical Procedures Companion, New Jersey: Prentice Hall.

- Papatheodorou A, Arvanitis P, (2009) 'Spatial evolution of airport traffic and air transport liberalisation: the case of Greece', Journal of Transport Geography, 17(5), 402-412.

- Percoco M, (2010) 'Airport activity and local development: evidence from Italy', Urban Studies, 47(11), 2427-2443.

- Polyzos S, (2019) Regional Development, $2^{\text {nd }}$ Edition, Athens: Kritiki Publications. (In Greek).

- Polyzos S, Tsiotas D, (2012) The Evolution and Spatial Dynamics of Coastal Cities in Greece, in Polyzos S (Ed.) Urban Development, Croatia: Intech Publications: 275-296.

- Psaraki-Kalouptsidi V, Kalakou S, (2011) 'Assessment of efficiency of Greek airports', Journal of Airport Management, 5(2), 170-186.

- Robertson J, (1995) 'Airports and economic regeneration', Journal of Air Transport Management, 2(2), 81-88.

- Rodrigue J.P, Comtois C, Slack B, (2013) The Geography of Transport Systems, New York: Routledge Publications.

- Sellner R, Nagl P, (2010) 'Air accessibility and growth-The economic effects of a capacity expansion at Vienna International Airport', Journal of Air Transport Management, 16(6), 325-329.

- Tsekeris T, (2011) 'Greek airports: efficiency measurement and analysis of determinants,' Journal of Air Transport Management, 17(2), 140-142.

- Tsiotas D, Polyzos S, (2013) 'Introducing a new centralities measure from the interregional road transportation network analysis in Greece'. Annals of Operations Research, 227(1), 93-127. 
- Tsiotas D, Polyzos S, (2015a) 'Analyzing the Maritime Transportation System in Greece: a Complex Network approach', Networks and Spatial Economics, 15(4), 981-1010.

- Tsiotas D, Polyzos S, (2015b) 'Decomposing multilayer transportation networks using complex network analysis: A case study for the Greek aviation network', Journal of Complex Networks, 3(4), 642-670.

- Tsiotas D, Polyzos S, (2018) 'The complexity in the study of spatial networks: an epistemological approach', Networks and Spatial Economics, 18(1), 1-32.

- Tsiotas D, Niavis S, Belias D, Sdrolias L, (2018) 'Modeling the International Tourism Demand as a Complex Network: the Case of the Global Inbound Tourism Market' International Conference on Strategic Innovative Marketing and Tourism (ICSIMAT 2018), Athens, Greece, 17-20 October 2018.

- Walpole R. E, Myers R. H, Myers S. L, Ye K, (2012) Probability \& Statistics for Engineers \& Scientists, ninth ed., New York, USA: Prentice Hall Publications.

- Zak D, Getzner M, (2014) 'Economic Effects of Airports in Central Europe: A Critical Review of Empirical Studies and Their Methodological Assumptions', Advances in Economics and Business, 2(2), 100-111.

\section{AUTHORS' BIO}

Dr Dimitrios Tsiotas is an Adjunct Lecturer at the Dept. of Regional and Economic Development (AUA) and at the Hellenic Open University. His research interests include network science, regional economics, statistical mechanics, transportation economics, and regional science.

Dr Spyros Niavis is a Researcher at the Dept. of Planning and Regional Development, University of Thessaly, Greece. His research interests include regional economics, efficiency and productivity analysis, maritime economics, regional development, and economic policy.

Professor Dr Serafeim Polyzos is a Professor at the Dept. of Planning and Regional Development, University of Thessaly, Greece. His research interests include regional economics and development, urban development and planning, project management, and project appraisal.

Artemis Papageorgiou, M.Sc. is an Aircraft Engineer, a Regional Planner, and a researcher in regional development, from University of Thessaly, Greece. His research interests include airport dynamics, spatial planning, and regional development. 